\title{
The Approaching New Grand Solar Minimum and Little Ice Age Climate Conditions
}

\author{
Nils-Axel Mörner \\ Paleogeophysics \& Geodynamics, Stockholm, Sweden \\ Email: morner@pog.nu \\ Received 7 October 2015; accepted 16 November 2015; published 19 November 2015 \\ Copyright () 2015 by author and Scientific Research Publishing Inc. \\ This work is licensed under the Creative Commons Attribution International License (CC BY). \\ http://creativecommons.org/licenses/by/4.0/ \\ (c) (i) Open Access
}

\begin{abstract}
By about 2030-2040, the Sun will experience a new grand solar minimum. This is evident from multiple studies of quite different characteristics: the phasing of sunspot cycles, the cyclic observations of North Atlantic behaviour over the past millennium, the cyclic pattern of cosmogenic radionuclides in natural terrestrial archives, the motions of the Sun with respect to the centre of mass, the planetary spin-orbit coupling, the planetary conjunction history and the general planetary-solar-terrestrial interaction. During the previous grand solar minima-i.e. the Spörer Minimum (ca 1440-1460), the Maunder Minimum (ca 1687-1703) and the Dalton Minimum (ca 18091821) - the climatic conditions deteriorated into Little Ice Age periods.
\end{abstract}

\section{Keywords}

Solar Variability, Grand Solar Minima, Little Ice Ages, The 2030-2040 Solar Minimum

\section{Introduction}

The solar activity exhibits a fairly regular alternation between solar maxima and solar minima (e.g. [1] [2]). The grand solar minima known as the Spörer Minimum (ca 1440-1460), the Maunder Minimum (ca 1687-1703) and the Dalton Minimum (ca 1809-1821) are all well known, not least because they correspond quite well with cold periods known as "Little Ice Ages" [3]-[5].

In the period 1997-2003, I chaired an INTAS project on Geomagnetism \& Climate; we concluded that we, in the middle of the $21^{\text {st }}$ century, had to be back in a new solar minimum with Little Ice Age climatic conditions [6] [7].

Several authors have made similar observations and claims [5]-[31]. 
Several of the papers in the Special Issue of PRP [1] addressed the question of an approaching new Solar Minimum. The conclusions [21] were quite straightforward: Obviously we are on our way into a new grand solar minimum. This sheds serious doubts on the issue of a continued, even accelerated, warming as proposed by the IPCC project.

This quite innocent—and very true—conclusion [21] made the publisher take the quite remarkable step to close down the entire scientific journal [32].

This closing down gave rise to turbulence and objections within the scientific community [31] [33]-[39]. It even became the incitement to a new book [2].

In this paper, I will review some of the leading facts for the proposition of an approaching Grand Solar Minimum and a related climatic deterioration of Little Ice Age type, in analogy with what happened during the last three solar minima, viz. the Dalton, Maunder and Spörer Minima.

\section{The Claim of Priority}

With respect to all the authors having claimed that we are approaching a solar minimum and/or a new Little Ice Age [1] [2] [5]-[31], there is hard, even meaningless, to try to identify a paper of priority (maybe [8]). Apparently, several authors had the same idea based on a verity of different data; heliomagnetic cyclicity, atmospheric production of radionuclides, planetary beat, history and cyclicity of various terrestrial variables.

What we can say, however, is that paper [25] by no means is a candidate for such a priority although this was claimed by media and some blogs [40]. There are many "pioneer" papers before that paper.

I am well aware of the saying: the true pioneers never (or at least seldom) get credit for the discovery.

We leave this discussion with references to a number of preceding papers [1] [5] [6]-[21].

\section{Predicting Solar Variability and Climate}

The validity of physical laws and driving forcing functions is revealed in the appearance in time; i.e., the evolutionary history of cosmos, the planetary system, the Earth-Moon system and the terrestrial processes. The base is a chronology set by dating or time-series with a stratigraphic order. In such records we observe the appearance and re-appearance of events and changes, which often form patterns. In these patterns, we may recognize forcing functions and cyclic patterns. In there cognitions of patterns and cycles, we not only make order of the past, but may also assess predictions of future changes [41].

The cyclic alternations between solar maxima and minima were found to correlate with periods of speeding-up and slowing-down in the Earth's rate of rotation as illustrated in Figure 1.

At the Spörer, Maunder and Dalton Grand Solar Minima the circulation pattern of the North Atlantic changed dramatically [5] as illustrated in Figure 2 [5] [11].

At the approaching New Grand Solar Minimum similar conditions are likely to re-occur [5] [11] [17] [28] [42]; i.e. a return to Little Ice Age conditions.

A return to cold climate conditions at around 2040 is also predicted in cyclicity of Barents Sea fish catch and the interchanges of Atlantic and Barents Sea water masses [43] [44].

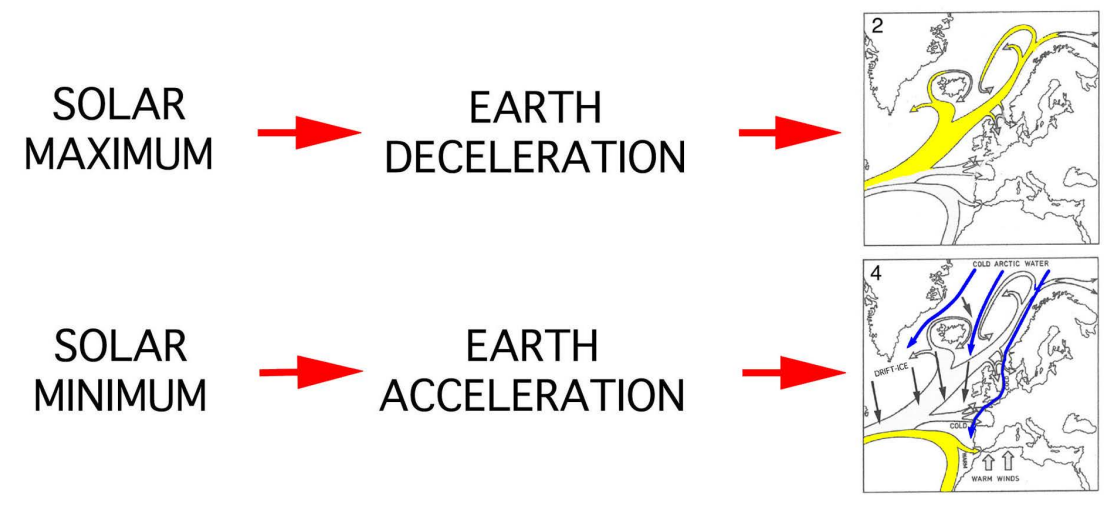

Figure 1. Relations among solar cycles, Earth's rate of rotation and the observed changes in the ocean circulation in the North Atlantic (from [5] [11]). 


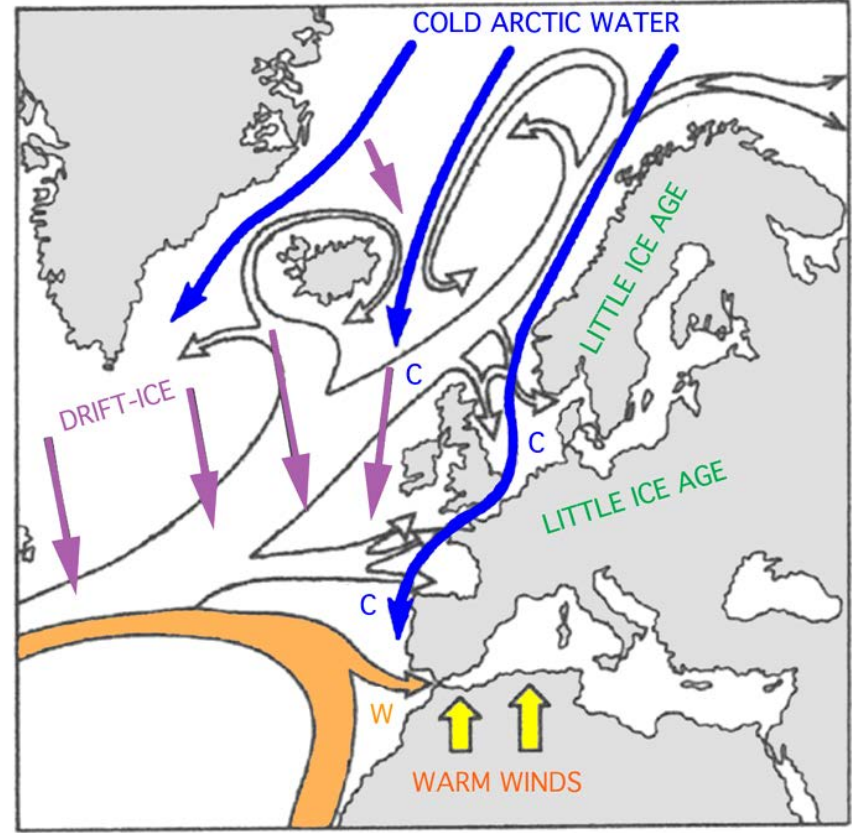

Figure 2. During the Spörer, Maunder and Dalton Minima, Earth’s rate of rotation speeded-up, the main Gulf Stream flow was directed SE:wards and Arctic water penetrated far down into the North Atlantic [5]. At the New Grand Solar Minimum similar conditions are likely to re-occur.

The analogy with the past three grand solar minima seems quite firm. At all those solar minima the North Atlantic circulation strongly deformed as illustrated in Figure 2 [5].

Therefore, the same is supposed to re-occur at the New Grand Solar Minimum at 2030-2040 [5] [11].

This was quite a revolutionary conclusion [5] [11] as it totally contradicted the scenario by the IPCC of a continually increasing warming over the next centuries [45].

The date of the New Solar Minimum has been assigned at around 2040 by Mörner et al. [6], at 2030-2040 by Velasco Herrera [27], and at around 2040 by Abdussamatov [23], implying a fairly congruent picture despite different ways of transferring past signals into future predictions.

In conclusion, we assign an age of the approaching New Grand Solar Minimum of about 2030-2040. This implies that we must expect cold conditions [11]—not warm conditions [45]—at the middle of the present century [11].

Figure 3 gives the cyclic phasing of the Gleisberg and De Vries cycles over the past 600 years with a prediction also for the $21^{\text {st }}$ century [6] [7] [9] [11]. This implies that we by mid $21^{\text {st }}$ century must expect cold climatic conditions and extensive ice expansion in the Arctic [11] —in total disagreement with the widely spread IPCC scenario of an open Arctic by 2050. Solar maxima occur in the mid $16^{\text {th }}$ century, in the early and late $18^{\text {th }}$ century and in the early and late $20^{\text {th }}$ century. Solar minima occur in mid $15^{\text {th }}$ century, in late $18^{\text {th }}$ century and in early and late $19^{\text {th }}$ century, indicating a new solar minimum in the med $21^{\text {st }}$ century.

Another way of estimating the changes is to use the cyclic pattern of the cosmogenic radionuclides (i.e. ${ }^{14} \mathrm{C}$ and ${ }^{10} \mathrm{Be}$ ) of the last 800 years with an extrapolation into the $21^{\text {st }}$ century [11]. This is illustrated in Figure 4 [11] [44]. It suggests that there will be a new minimum around 2040.

Hansen [46] observed that the sea level changes in the Kattegatt-Baltic region were dominated by lunar tidal forces. He documented the observed changes for the last 300 years and predicted them for the coming 200 years. Major low levels (in the order of $3-4 \mathrm{~cm}$ ) occur at 1809 (i.e. in the Dalton Minimum) and will re-occur in 2034 according to Hansen [47], fitting very well with the notion of a New Grand Solar Minimum around 2030-2040. It also opens new perspectives on the 60 year cycle [29] [39].

Wilson [19] showed that solar variability is primarily caused by a spin-orbital coupling between Venus, Earth and Jupiter (VEJ). This is illustrated in Figure 5 [19] [28]. 


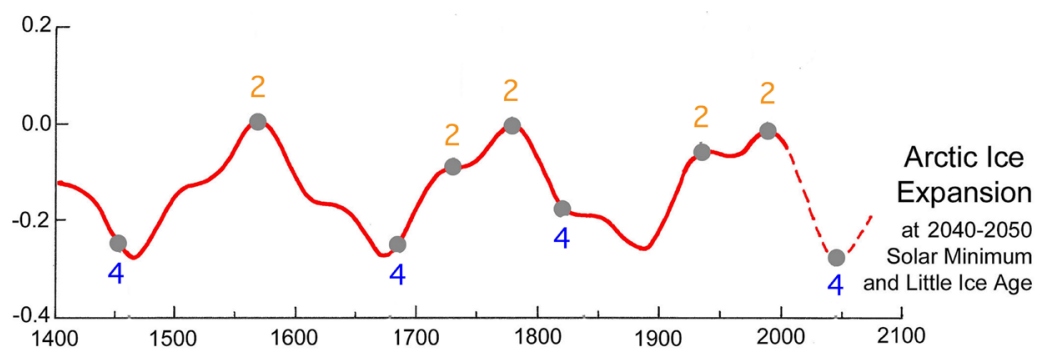

Figure 3. Cyclic phasing of the combined "Gleisberg” and De Vries Cycles over the last 600 years giving a new Solar Minimum at about 2040-2050 with cold climate conditions and major ice expansion in the Arctic (from [9] [11]). Vertical scale gives temperature in centigrade.

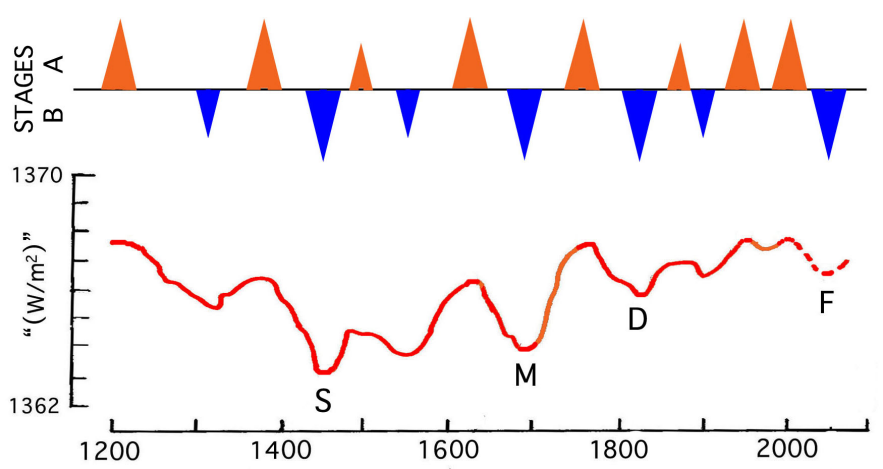

Figure 4. Atlantic warm (A) and cold (B) periods (above), and solar variability (below) with the Spörer (S), Maunder (M), Dalton (D) and Future (F) grand solar minima of Figure 2 character marked (from [41]). The "solar irradiance" curve [46] records the changes in Solar Wind, not irradiance, and must hence be relabelled "a curve of the changes in Solar Wind activity" (therefore their vertical scale of irradiance is put in brackets and quotation marks).

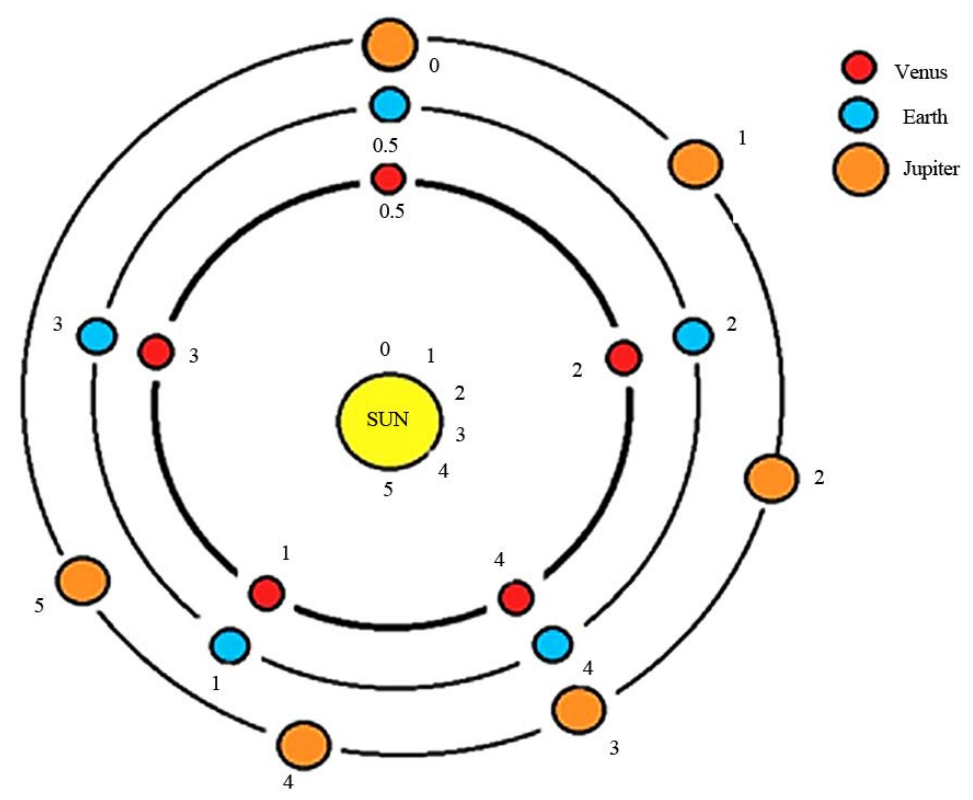

Figure 5. Wilson's VEJ tidal-torqueing model [19], providing an 11.07 yr beat period on the Sun. It forms the base for Salvador's [20] mathematical model of the sunspot cycles. 
Salvador [20] presented a mathematical model of the sunspot cycles based on Wilson's tidal-torque model of Figure 5. The model had an 85\% correlation with the sunspot numbers observed for 1749-2013, and made "a reasonable representation of the sunspot cycles for the past $1000 \mathrm{yr}$ ”. Therefore, it justified an extrapolation for the next century, as shown in Figure 6.

The Figure 6 prediction gives an extended low up to 2160 with the lowest values reached within the period 2028-2042; i.e. just where we expect the New Grand Solar Minimum to occur [1] [2].

In 2015, Salvador extended his analysis over the last 4000 years [28], comparing his model with the observed ${ }^{10}$ Be variations [48], as illustrated in Figure 7.

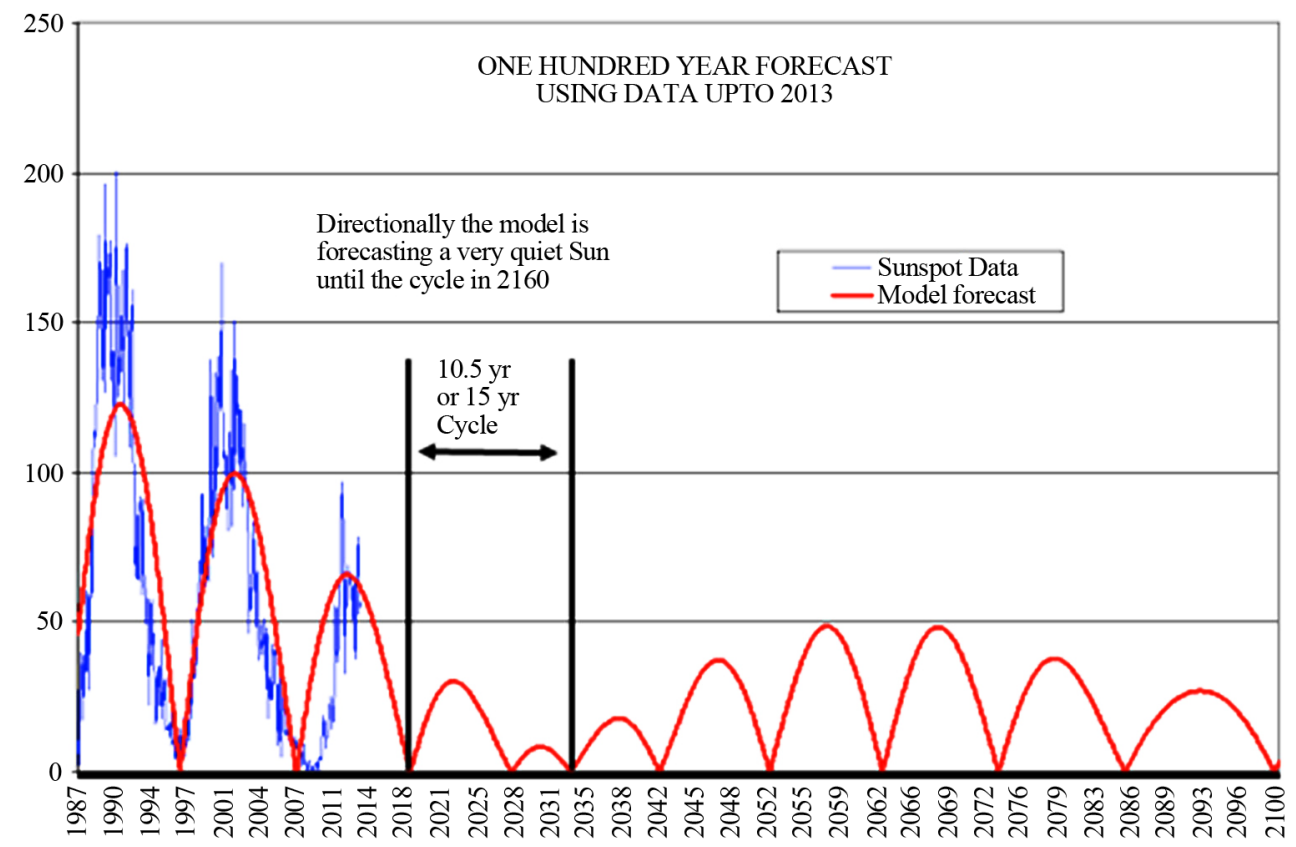

Figure 6. A comparison of monthly sunspot numbers from 1987 to 2013 (in blue) with the absolute value of the correlation model (in red), derived using data up to 2013 and the extended forecast to $2100[20]$.

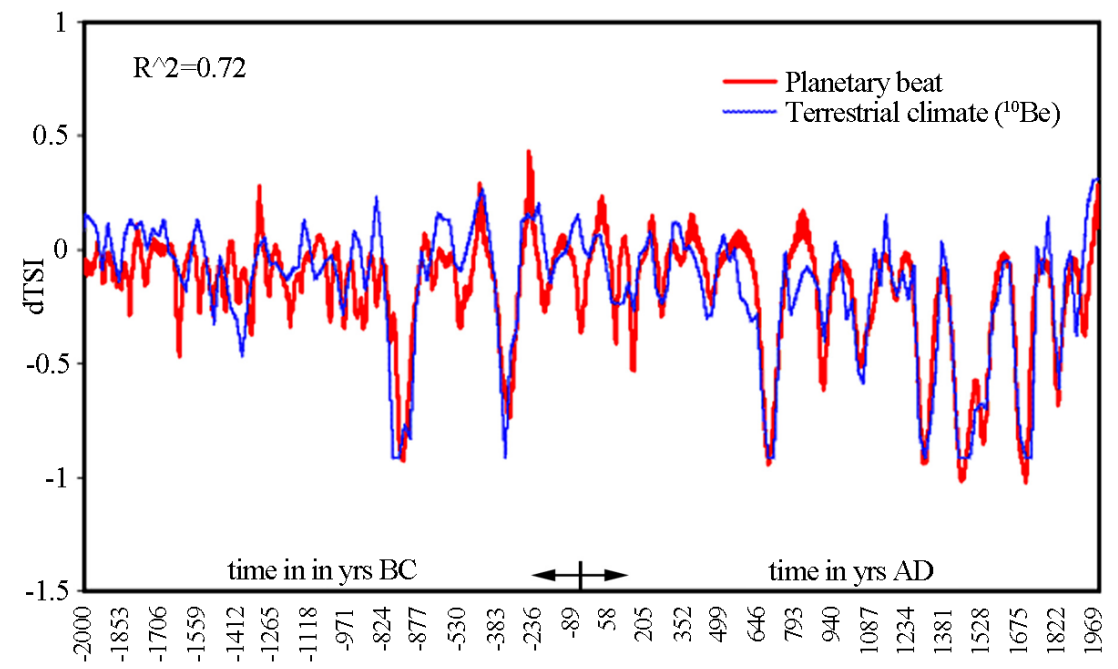

Figure 7. Comparison between planetary beat according to the VEJ SOC Solar System Resonance Model of Salvador [20] based on the VEJ theory of Wilson [19], and the dTSI as calculated from terrestrial ${ }^{10} \mathrm{Be}$ variations [48]. The agreement is striking over 4000 years. We take this as a confirmation of the planetary-solar-terrestrial interaction [28]. 


\section{Discussion}

The Earth experienced speeding-up periods at grand solar minima and slowing-down periods at grand solar maxima [5] [17] [29] [49]. This controls the main ocean surface circulation. In the North Atlantic this is seen in the beat and directional shifts of the Gulf Stream [5] [9] [11] as illustrated in Figure 1. It is also recorded in the rises and falls in sea level in the Indian Ocean (Figure 2 of [29]). The link between solar variability and terrestrial responses must go via the interaction of the Solar Wind with the Earth's magnetospher [5] [17] [42] [44] [49] as illustrated in Figure 8.

The origin of solar variability may be generated in the solar core [50], at the tachocline [51] or at the surface [52] [53]. The driving forces are likely to be spin-orbital effects from the planets as proposed by Wilson [19] and established by Salvador [20] [28] as illustrated in Figure 6 and Figure 7.

Another important factor must be the constant motions of the planetary bary-centra inside and outside the Sun providing an "excenter-wheel motor" [30], fully capable to affect the radioactive interior, the tachocline and the surface in ways generation cyclically occurrence in the solar variability.

\section{Conclusions}

The phasing of the solar cycles gives a clear message for the middle of the century: there will be a New Grand Solar Minimum [1]. This is also the case when we consider the cyclic relations between Earth's rotation, ocean circulation and Arctic climate [5] [17] [29] as illustrated in Figure 1 and Figure 4.

During the last three grand solar minima—-the Spörer, Maunder and Dalton Minima-global climate experienced Little Ice Age conditions [3]-[5]. Arctic water penetrated to the south all the way down to Mid Portugal, and Europe experienced severe climatic conditions as recorded in Figure 1 and Figure 2. The Arctic ice cover expanded significantly [11].

By 2030-2040 we will be in a New Grand Solar Minimum (cf. Figure 3, Figure 4), which by analogy to past minima must be assumed to lead to a significant climatic deterioration with ice expansion in the Arctic [5] [11].

The mathematical model by Salvador [20] [28] seems to provide an excellent tool for the prediction of future sunspot variations (Figure 5, Figure 6).

We now seem to be in possession of quite convergent data, indicating that we by 2030-2040 will be in a New Grand Solar Minimum.

This precludes a continual warming as claimed by the IPCC project [45]. Instead of this, we are likely to face a new Little Ice Age (Figure 2).

So, when Hunter [54] talked about "Thermageddon: countdown to 2030", exactly the opposite is likely to by the true climatic shift [34] [55]; viz. a significant cooling, maybe even a Little Ice Age, and by no means any disastrous warming.

Consequently, by 2030-2040, it seems most likely that climate reality-a cooling associated with a grand solar minimum—-will imply a long nose to the IPCC concept [45] and the idea of a thermageddon countdown [54].

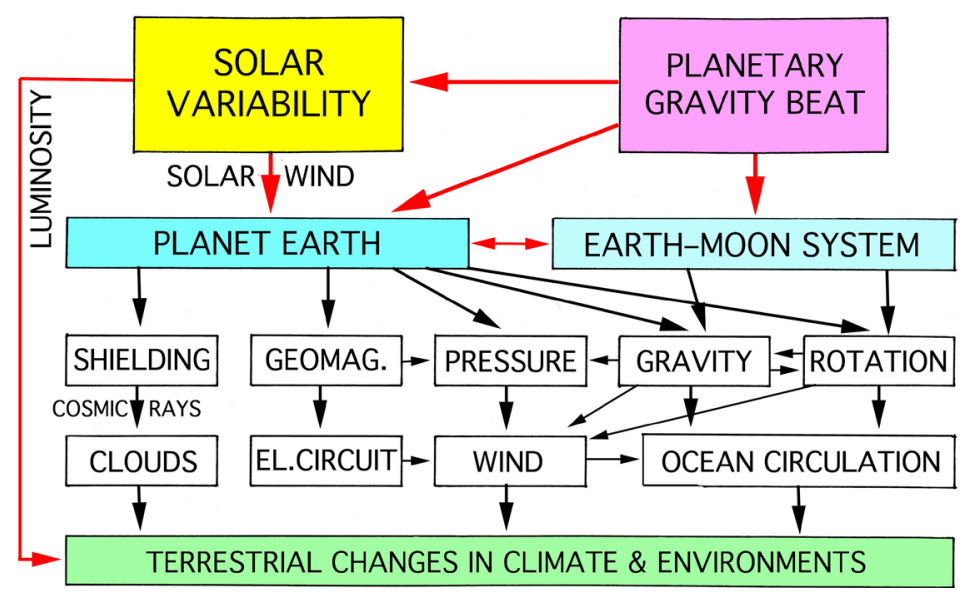

Figure 8. Planetary beat processes and the spectrum of terrestrial variables affected [17] [28] [42] [44]. 
Not only is it a question about facts [36] [37] but also a respect to geoethical principles [37] [38].

\section{References}

[1] Mörner, N.-A., Tattersall, R. and Solheim, J.-E. (2913) Pattern in Solar Variability, Their Planetary Origin and Terrestrial Impact. Pattern Recognition in Physics, 1, 203-204. www.pattern-recogn-phys.net/special_issue2.html

[2] Mörner, N.-A. (2015) Planetary Influence on the Sun and the Earth, and a Modern Book-Burning. Nova Science Publishers, New York.

[3] Eddy, J.A. (1976) The Maunder Minimum. Science, 192, 1189-1202. http://dx.doi.org/10.1126/science.192.4245.1189

[4] Lamb, H.H. (1979) Climate Variation and Changes in the Wind and Ocean Circulation. Quaternary Research, 11, 120. http://dx.doi.org/10.1016/0033-5894(79)90067-X

[5] Mörner, N.-A. (2010) Solar Minima, Earth’s Rotation and Little Ice Ages in the Past and in the Future. The North Atlantic-European Case. Global Planetary Change, 72, 282-293. http://dx.doi.org/10.1016/j.gloplacha.2010.01.004

[6] Mörner, N.-A., Nevanlinna, H., Dergachev, V., Shumilov, O., Raspopov, O., Abrahamsen, N., Pilipenko, O., Trubikhin, V. and Gooskova, E. (2013) Geomagnetism and Climate V: General Conclusions. EGS-AGU-EGU, Nice, Abstracts CL2.08.

[7] Mörner, N.A., Nenanlinna, H. and Shumilov, O. (2013) Past Climate Changes, Origin And Predictions. EGS-AGUEGU, Nice, Abstracts CL2.07.

[8] Landscheidt, T. (2003) New Little Ice Age Instead of Global Warming. Energy and Environment, 14, 327-350. http://dx.doi.org/10.1260/095830503765184646

[9] Mörner, N.-A. (2006) 2500 Years of Observations, Deductions, Models and Geoethics. Bollettino della Società Geologica Italiana, 125, 259-264.

[10] Charvátová, I. (2009) Long-Term Predictive Assessments of Solar and Geomagnetic Activities Made on the Basis of the Close Similarity between the Solar Inertial Motions in the Intervals 1840-1905 and 1980-2045. New Astronomy, 14, 25-30. http://dx.doi.org/10.1016/j.newast.2008.04.005

[11] Mörner, N.-A. (2011) Arctic Environment by the Middle of This Century. Energy \& Environment, 22, 207-218. http://dx.doi.org/10.1260/0958-305X.22.3.207

[12] D’Aleo, J. (2011) Chapter 10: Solar Changes and Climate. In: Easterbrook, D.J., Ed., Evidence-Based Climate Science, Elsevier, Amsterdam, 253-276. http://dx.doi.org/10.1016/B978-0-12-385956-3.10010-5

[13] Archibald, D. (2011) Chapter 11: The Current Solar Minimum and Its Consequences for Climate. In: Easterbrook, D.J., Ed., Evidence-Based Climate Science, Elsevier, Amsterdam, 277-287. http://dx.doi.org/10.1016/B978-0-12-385956-3.10011-7

[14] Casey, J.L. (2011) Cold Sun: A Dangerous “Hibernation” of the Sun Has Begun. Trafford Publishing, Bloomington.

[15] Scafetta, N. (2012) Multi-Scale Harmonic Model for Solar and Climate Cyclical Variation throughout the Holocene Based on Jupiter-Saturn Tidal Frequencies plus the 11-Year Solar Dynamo Cycle. Journal of Atmospheric and SolarTerrestrial Physics, 80, 296-311. http://dx.doi.org/10.1016/j.jastp.2012.02.016

[16] Cionco, R.G. and Compagnucci, R.H. (2012) Dynamical Characterization of the Last Prolonged Solar Minima. Advances in Space Research, 50, 1434-1444. http://dx.doi.org/10.1016/j.asr.2012.07.013

[17] Mörner, N.-A. (2013) Planetary Beat and Solar-Terrestrial Responses. Pattern Recognition in Physics, 1, 107-116. http://dx.doi.org/10.5194/prp-1-107-2013

[18] Solheim, J.-E. (2013) Signals from the Planets, via the Sun to the Earth. Pattern Recognition in Physics, 1, 177-184. http://dx.doi.org/10.5194/prp-1-177-2013

[19] Wilson, I.R.G. (2013) The Venus-Earth-Jupiter Spin-Orbit Coupling. Pattern Recognition in Physics, 1, 147-158. http://dx.doi.org/10.5194/prp-1-147-2013

[20] Salvador, R. (2013) A Mathematical Model of the Sunspot Cycle for the Past 1000 yr. Pattern Recognition in Physics, 1, 117-122. http://dx.doi.org/10.5194/prp-1-117-2013

[21] Mörner, N.-A., Tattersall, R., Solheim, J.-E., Charvatova, I., Scafetta, N., Jelbring, H., Wilson, J.R., Salvador, R., Willson, R.C., Hejda, P., Soon, W., Velasco Herrera, V.M., Humlum, O., Archibald, D., Yndestad, H., Easterbrook, D.J., Casey, J., Gregori, G. and Henriksson, G. (2013) General Conclusions regarding the Planetary-Solar-Terrestrial Interaction. Pattern Recognition in Physics, 1, 205-206. http://dx.doi.org/10.5194/prp-1-205-2013

[22] Charvátová, I. and Hejda, P. (2014) Responses of the Basic Cycles of 178.7 and 2402 yr in Solar-Terrestrial Phenomena during the Holocene. Pattern Recognition in Physics, 2, 21-26. http://dx.doi.org/10.5194/prp-2-21-2014

[23] Abdussamatov, H.J. (20114) Long-Term Negative Average Annual Energy Balance of the Earth Leads to the Little Ice 
Age. Proceedings of the XVIII Conference on Solar and Solar-Terrestrial Physics 2014, Pulkovo, 20-25 October 2014, 3-6.

[24] Georgieva, K., Nagovitsyn, Y. and Kirov, B. (2014) Solar Magnetic Field and Terrestrial Climate. Proceedings of the XVIII Conference on Solar and Solar-Terrestrial Physics 2014, Pulkovo, 20-25 October 2014, 99-104.

[25] Shepherd, S.I., Zharkov, S.I. and Zharkova, V.V. (2014) Prediction of Solar Activity from Solar Background Magnetic Field Variations in Cycles 21-23. Astrophysics Journal, 795, 46. http://dx.doi.org/10.1088/0004-637X/795/1/46

[26] Cionco, R.G. and Soon, W. (2015) A Phenomenological Study of the Timing of Solar Activity Minima of the Last Millennium through Modelling the Sun-Planets Interaction. New Astronomy, 34, 164-171. http://dx.doi.org/10.1016/j.newast.2014.07.001

[27] Velasco Herrera, V.M., Mendoza, B. and Velasco Herrera, G. (2015) Reconstruction and Prediction of the Total Solar Irradiance; from the Medieval Warm Period to the 21st Century. New Astronomy, 34, 221-233. http://dx.doi.org/10.1016/j.newast.2014.07.009

[28] Mörner, N.-A. (2015) Chapter 2: Planetary-Solar-Terrestrial Interaction: A Review. In: Mörner, N.-A., Ed., Planetary Influence on the Sun and the Earth, and a Modern Book-Burning, Nova Science Publishers, Hauppauge, 5-32.

[29] Mörner, N.-A. (2015) Chapter 4: Multiple Planetary Influences on the Earth. In: Mörner, N.-A., Ed., Planetary Influence on the Sun and the Earth, and a Modern Book-Burning, Nova Science Publishers, Hauppauge, 39-49.

[30] Mörner, N.-A. (2015) Chapter 9: Concluding Remarks. In: Mörner, N.-A., Ed., Planetary Influence on the Sun and the Earth, and a Modern Book-Burning, Nova Science Publishers, Hauppauge, 109-120.

[31] Mörner, N.-A., Monckton, C., Gregori, G., Tattersall, R., Solheim, J.-E., Scafetta, N., Charvatova, I., Jelbring, H., Wilson, J.R., Salvador, R., Willson, R.C., Hansen, J.M., Humlum, O., Karlén, W., Nemec, N., Kalenda, P., Archibald, D., Velasco Herrera, V.M., Grandpierre, A. and Easterbrook, D.J. (2015) Chapter 17: Conclusions and Perspectives. In: Mörner, N.-A., Ed., Planetary Influence on the Sun and the Earth, and a Modern Book-Burning, Nova Science Publishers, Hauppauge, 187-190.

[32] Mörner, N.-A. (2015) Chapter 10: An Unbelievable Decision. In: Mörner, N.-A., Ed., Planetary Influence on the Sun and the Earth, and a Modern Book-Burning, Nova Science Publishers, Hauppauge, 123-126.

[33] Mörner, N.-A. (2015) Chapter 11: Introduction to Section B. In: Mörner, N.-A., Ed., Planetary Influence on the Sun and the Earth, and a Modern Book-Burning, Nova Science Publishers, Hauppauge, 129-134.

[34] Monckton of Brenchley, C. (2015) Chapter 12: The Thermaggedon Cult Strikes Again. In: Mörner, N.-A., Ed., Planetary Influence on the Sun and the Earth, and a Modern Book-Burning, Nova Science Publishers, Hauppauge, 135-138.

[35] Gregori, G. (2015) Chapter 13: Science: An Historical Perspective. In: Mörner, N.-A., Ed., Planetary Influence on the Sun and the Earth, and a Modern Book-Burning, Nova Science Publishers, Hauppauge, 139-146.

[36] Monckton of Brenchley, C. (2015) Chapter 14: What Is Science? In: Mörner, N.-A., Ed., Planetary Influence on the Sun and the Earth, and a Modern Book-Burning, Nova Science Publishers, Hauppauge, 149-165.

[37] Mörner, N.-A. (2015) Chapter 15: Climate Fundamentalism. In: Mörner, N.-A., Ed., Planetary Influence on the Sun and the Earth, and a Modern Book-Burning, Nova Science Publishers, Hauppauge, 167-174.

[38] Mörner, N.-A. (2015) When Reason Sleeps, Monster Take Wings. In: Mörner, N.-A., Ed., Planetary Influence on the Sun and the Earth, and a Modern Book-Burning, Nova Science Publishers, Hauppauge, 177-184.

[39] Mörner, N.-A. (2015) Chapter 18: Concluding Editorial Remarks. In: Mörner, N.-A., Ed., Planetary Influence on the Sun and the Earth, and a Modern Book-Burning, Nova Science Publishers, Hauppauge, 191-193.

[40] The Telegraph, July 11, 2015.

http://www.telegraph.co.uk/news/science/11733369/Earth-heading-for-mini-ice-age-within-15-years.html?WT.mc_id= e_DM30959\&WT.tsrc=email\&etype=Edi_FPM_New\&utm_source=email\&utm_medium=Edi_FPM_New_2015_07_1 1\&utm_campaign=DM30959

[41] Mörner, N.-A. (2015) An Editorial Note on the Desperate Search for a Stable Point. In: Mörner, N.-A., Ed., Planetary Influence on the Sun and the Earth, and a Modern Book-Burning, Nova Science Publishers, Hauppauge, 121.

[42] Mörner, N.-A. (2012) Planetary Beat, Solar Wind and Terrestrial Climate. In: Escaropa, C.D. and Berós Cruz, A.F., Eds., Solar Wind: Emission, Technology and Impacts, Nova Science Publishers, Hauppauge, 47-66.

[43] Klyashtorin, L.B., Borisov, V. and Lyubushin, A. (2009) Cyclic Changes of Climate and Major Commercial Stocks of the Barents Sea. Marine Biology Research, 5, 4-17. http://dx.doi.org/10.1080/17451000802512283

[44] Mörner, N.-A. (2013) Solar Wind, Earth’s Rotation and Changes in Terrestrial Climate. Physical Review \& Research International, 3, 117-136.

[45] IPCC (2007) Climate Change. Cambridge University Press, Cambridge.

[46] Hansen, J.M. (2015) Chapter 5: Sea-Level Effects on NOA and AMO: Synchronization and Amplitude Locking by the 
Lunar Nodal Oscillation in the North Sea and the Baltic Embayment. In: Mörner, N.-A., Ed., Planetary Influence on the Sun and the Earth, and a Modern Book-Burning, Nova Science Publishers, Hauppauge, 51-77.

[47] Bard, E., Raisbeck, G., Yiou, F. and Jouzel, J. (2000) Solar Irradiance during the Last 1200 Years Based on Cosmogenic Nuclides. Tellus, 52B, 985-992. http://dx.doi.org/10.1034/j.1600-0889.2000.d01-7.x

[48] Steinhilber, F., Abreu, J.A., Beer, J., et al. (2012) 9,400 Years of Cosmic Radiation and Solar Activity from Ice Cores and Tree Rings. Proceedings of the National Academy of Sciences of the United States of America, 109, 5967-5971. http://dx.doi.org/10.1073/pnas.1118965109

[49] Mörner, N.-A. (1996) Global Change and Interaction of Earth Rotation, Ocean Circulation and Paleoclimate. Brazilian Academy of Sciences, 68, 77-94.

[50] Grandpierre, A. (2015) Chapter 8: The Origin of Solar Activity: Local Thermonuclear Runways in Hot Bubbles and Their Triggers. In: Mörner, N.-A., Ed., Planetary Influence on the Sun and the Earth, and a Modern Book-Burning, Nova Science Publishers, Hauppauge, 91-108.

[51] Abreu, J.A., Beer, J., Ferriz-Mas, A., McCracken, K.G. and Steinhilber, F. (2012) Is There a Planetary Influence on Solar Activity? Astronomy \& Astrophysics, A88, 1-9. http://dx.doi.org/10.1051/0004-6361/201219997

[52] Jelbring, H. (2013) Energy Transfer in the Solar System. Pattern Recognition in Physics, 1, 165-176. http://dx.doi.org/10.5194/prp-1-165-2013

[53] Mörner, N.-A. (2015) Chapter 7: The Bölling/Alleröd-Younger Dryas Oscillations. In: Mörner, N.-A., Ed., Planetary Influence on the Sun and the Earth, and a Modern Book-Burning, Nova Science Publishers, Hauppauge, 79-89.

[54] Hunter, R. (2003) Thermageddon: Countdown to 2030. Arcade Publishing, New York, 288 p.

[55] Mörner, N.-A. (2015) Editorial Note on Thermageddon. In: Mörner, N.-A., Ed., Planetary Influence on the Sun and the Earth, and a Modern Book-Burning, Nova Science Publishers, Hauppauge, 138. 